\title{
CORRIGENDA
}

\section{Trial of labor after cesarean: attempted operative vaginal delivery versus emergency repeat cesarean, a prospective national cohort study}

AL Rietveld, N Kok, BM Kazemier, CJM de Groot and PW Teunissen

Journal of Perinatology (2015) 35, 310; doi:10.1038/jp.2014.242

Correction to: Journal of Perinatology advance online publication, 4 December 2014; doi:10.1038/jp.2014.216
Following publication of this article, the authors noticed that there was an error in the Acknowledgements section regarding the Netherlands Perinatal Registry number used by the authors. The correct registration number is ' 12.02 '.

\section{Multiples and parents of multiples prefer same arm randomization of siblings in neonatal trials}

J Bernardo, A Nowacki, R Martin, JM Fanaroff and AM Hibbs

Journal of Perinatology (2015) 35, 310; doi:10.1038/jp.2015.13

Correction to: Journal of Perinatology (2015) 35, 208-213; doi:10.1038/jp.2014.192
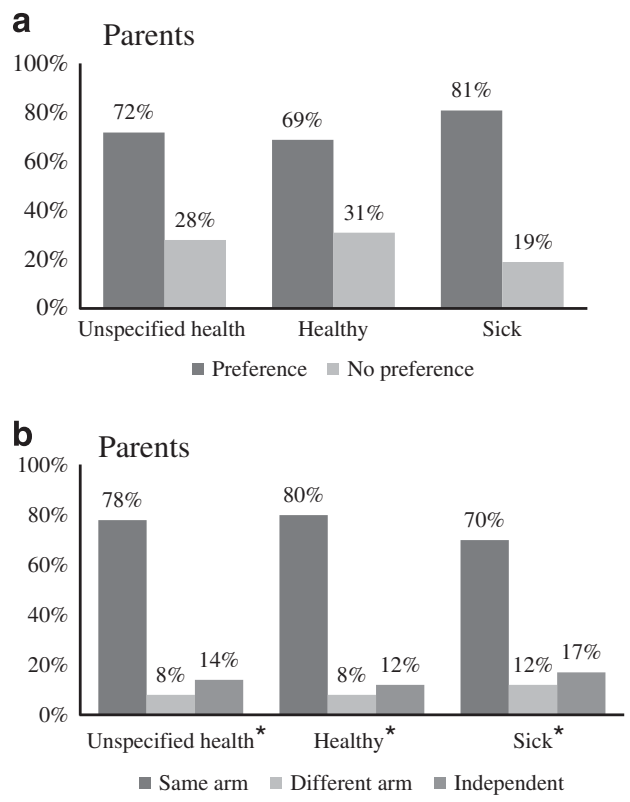

Figure 1. Parents and multiples preference on randomization approach. Parents of multiples and adult multiples who have a preference on how multiples are randomized within clinical trials based on health status (a) and which method (same arm, different arm, independent randomization) is most preferred $(\mathbf{b})$. In each of the six settings, same arm randomization was the most preferred ( $X^{2}$ goodness of fit test, all $P<0.001)$. 